\title{
Spectral generalization gradients from pigeons as a function of response latency ${ }^{1}$
}

\author{
WILLIAM M. BAKER AND MORRIS K. HOLLAND
} DUKE UNIVERSITY

Generalization gradients on wavelength were obtained from pigeons using a discrete trials procedure. For a group tested with $3 \mathrm{sec}$ trials, it was found that gradients produced by responses of shorter latencies showed greater extent of generalization than did gradients produced by responses of longer latencies. This relationship was also shown to hold when latencies were experimentally controlled by training different groups of animals on trials of differing lengths.

In an earlier experiment (Holland \& Baker, 1967) generalization gradients on wavelength were obtained from pigeons using a brief discrete trials procedure and employing probability of peck as a response measure. The current paper examines the relationship between the latency of the responses and the extent of the generalization gradients produced at given latencies.

Subjects

Twenty-four White Carneaux pigeons were used, maintained at $80 \%$ of their ad lib weights. All were experimentally naive.

\section{Apparatus}

The pigeons worked in four identical darkened cubical experimental chambers. The keys were springloaded plates of Plexiglas illuminated from behind by Bausch and Lomb Model 33-86-25 monochromators. Individual shutters for each box were solenoidactivated plates mounted in the path of the beam. Reinforcements were provided from grain magazines accessible through 3 in. circular holes below the keys. All control, timing, schedule, and analysis functions were provided by a LINC computer operating on-line. Responses were sensed by the LINC. The latency of the responses was timed by a clock internal to the LINC which operated in .05 sec units. Nethed

Experiment 1. Following magazine training, 12 birds were trained by the method of approximation to peck a key illuminated by $550 \mathrm{~m} \mu$. After 100 continuously reinforced responses with the shutter open, 6 sec discrete trials were introduced. The animals were run daily on discrete trials for the next 13 days, during which certain parameters were slowly changed: percent reinforcement was reduced from $100 \%$ to $10 \%$; trial time was reduced from 6 to $3 \mathrm{sec}$; and daily number of trials given was increased from 100 to 200. The animals were then run for six days on $3 \mathrm{sec}$ trials and $10 \%$ reinforcement. Throughout training and testing, trials were terminated either when the allotted trial time had elapsed or when a peck occurred. During the last six days of training all birds were responding essentially to every trial.
The 11 test stimuli used for the generalization test consisted of monochromatic values from 500 to $600 \mathrm{~m} \mu$, at $10 \mathrm{~m} \mu$ intervals. Generalization testing occurred on four consecutive days and included 4000 trials. Pecking was maintained by giving a noncontingent "free" feeding following a $20 \mathrm{sec}$ blackout period at intervals throughout the test.

Experiment 2. Training and testing procedures were the same as in Experiment 1, with the following exceptions: Four weeks of training to $550 \mathrm{m \mu}$ were given, the last two weeks of which consisted of daily sessions of 250 trials with $5 \%$ random reinforcement. Three groups of four birds each were trained and tested on 1,3 , and $5 \mathrm{sec}$ trials. Half of each group was run with constant 2 sec intertrial times, and half with variable intertrial times with peck-initiated delay, such than an intertrial response caused the onset of the next trial to be postponed. Generalization data were obtained from one day of testing, consisting of approximately 500 trials, Immediately following the four week training period. No interpolated feedings were given during the test. Resulfs and Discussion

Experiment 1. The relation between stimulus exposure time and extent of generalization is shown in Fig. 1. In this figure, gradients produced in the first $0.5 \mathrm{sec}$ of the trials, the middle $2 \mathrm{sec}$, and the last $0.5 \mathrm{sec}$ are presented for comparison. Since fast pecks reduce opportunities for slow pecks, the

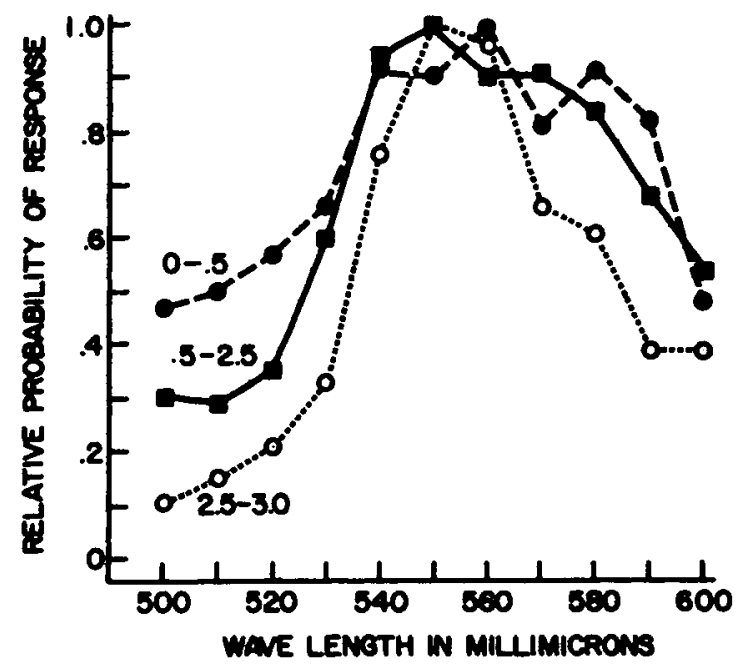

Fig. 1. Relative generalization gradients produced during the first $\mathbf{0 . 5}$ $\mathrm{sec}$, the middle $2 \mathrm{sec}$, and the last $0.5 \mathrm{sec}$ of the $3 \mathrm{sec}$ trials in Experiment 1 . The reduced number of opportunities for slower pecks is taken into account. 


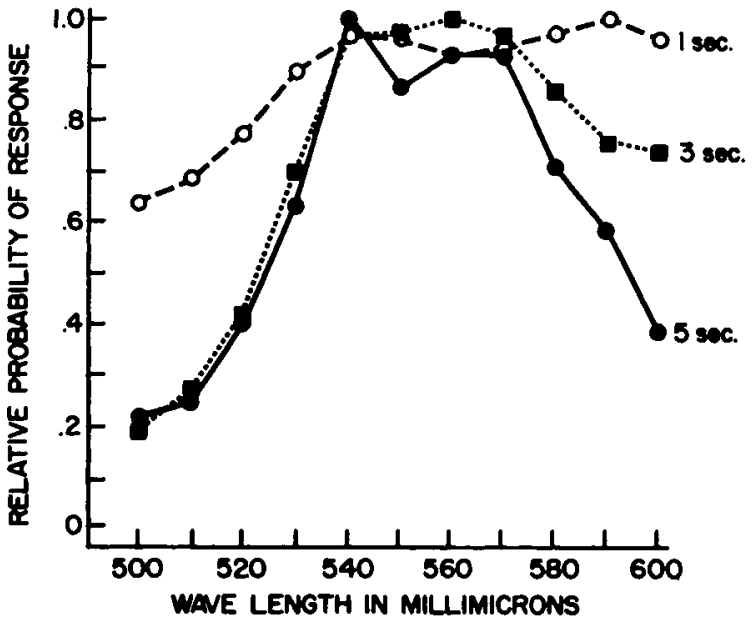

Fig. 2. Relative generalization gradients produced by the 1,3 , and $5 \mathrm{sec}$ trial groups of Experiment 2.

gradients shown are transformed. They are based upon the number of responses made in these intervals divided by the number of opportunities available. The resulting values were then scaled to allow slope comparisons. The gradients of relative generalization shown in Fig. 1 suggest a "latency-accuracy" function, such that the longer the stimulus exposure time preceding a peck, the relatively greater the tendency to peck only to values close to the training stimulus. In Experiment 1 response latency was not under direct experimental control, except insofar as the birds learned to peck within the 3 sec trial time. Consequently, the gradient produced from slow pecks tended to come more from periods near extinction than the gradient produced from fast pecks. Due to the interpolated feedings, however, these periods were distributed throughout the test.
Experiment 2. The second experiment controlled peck latency by training and testing birds on 1,3 , and 5 sec trials. This manipulation produced groups with different average latencies and, consequently, different average durations of stimulus exposure. Average latency of response was .72 sec for the $1 \mathrm{sec}$ group, $1.38 \mathrm{sec}$ for the $3 \mathrm{sec}$ group, and 1.66 $\mathrm{sec}$ for the $5 \mathrm{sec}$ group. The different gradients produced by these groups are seen in Fig. 2 and closely resemble the intragroup gradients from Experiment 1, in Fig. 1. The relative flatness of the 1 sec gradient in Fig. 2, as compared with the gradients in Fig. 1, may be due to the slightly different training and testing procedures used in the two experiments. Another possibility is that birds trained on $1 \mathrm{sec}$ trials were more under the control of stimulus onset than hue, since only diligent attention to that cue enabled them to peck before the trials were terminated.

As in the previous experiment, there is a tendency for responses of longer latency to result in gradients with a lesser extent of generalization. However, whereas in the previous experiment longer latency and sharper generalization gradients could both be independent effects of the extinction process, the current training provided differential latencies which were characteristic throughout the generalization test, thus lending more plausibility to a direct relationship between stimulus exposure time and extent of generalization.

\section{References}

HOLLAND, M. K., \& BAKER, W. M. Spectral generalization testing with pigeons using brief discrete trials. Psychon. Sci., 1968, 3, 1. Note

1. This research was supported by a NASA training grant to the second author and by grants MH 06661 and MH 08351 from NIH to C. Alan Boneau. 